\title{
Pneumatic Performance of the Boussignac CPAP System in Healthy Humans
}

\author{
Maria Sehlin RPT MSc, Siv Sandkvist Törnell MD, Fredrik Öhberg PhD, \\ Göran Johansson MSc, and Ola Winsö MD PhD
}

\begin{abstract}
BACKGROUND: The Boussignac continuous positive airway pressure (CPAP) device effectively treats acute pulmonary edema, but data on airway pressure with the Boussignac CPAP system are sparse. OBJECTIVE: To evaluate the Boussignac CPAP system's ability to maintain stable inspiratory and expiratory pressure levels, and to evaluate perceived exertion during breathing with the Boussignac CPAP system. METHODS: With 18 healthy volunteers we recorded airway pressure and air flow during 10 -min sessions at $5.0,7.5$, and $10.0 \mathrm{~cm} \mathrm{H}_{2} \mathrm{O}$. The participants were blinded to the sequence of the CPAP levels. Each session was ended with 10 forced breaths. We measured perceived exertion with the Borg category ratio 10 (Borg CR10) scale. RESULTS: When the participants breathed at $20 \%$ of vital capacity and a peak expiratory flow of $14 \%$ of $^{F E V_{1}}$, the maximum pressure difference between inspiration and expiration was $4.0 \mathrm{~cm} \mathrm{H}_{2} \mathrm{O}$ at $\mathrm{CPAP}$ $10 \mathrm{~cm} \mathrm{H}_{2} \mathrm{O}$. The changes in airway pressure were never large enough to reduce airway pressure to below zero. During the forced breaths, the expiratory volume was 38-42\% of vital capacity and peak expiratory flow was $49-56 \%$ of $\mathrm{FEV}_{1}$. As air flow increased, both the drop in inspiratory airway pressure and the increase in expiratory airway pressure increased. CONCLUSIONS: With CPAP, pressure changes are considered to be associated with increased work of breathing. The device's pneumatic performance is adequate during normal breathing with low air flow, but during forced breathing (high air flow) it did not maintain stable airway pressure, which could increase the work of breathing and cause respiratory fatigue. Thus, the Boussignac CPAP system might be less suitable for a patient breathing at a higher frequency. Key words: CPAP; continuous positive airway pressure; noninvasive ventilation; air flow; airway pressure; Borg CR10 scale; flow resistor. [Respir Care 2011;56(6):818-826. (C) 2011 Daedalus Enterprises]
\end{abstract}

\section{Introduction}

Continuous positive airway pressure (CPAP) is used to treat respiratory insufficiency due to acute cardiogenic pulmonary edema ${ }^{1-3}$ and sleep apnea, ${ }^{4}$ and to prevent or treat postoperative pulmonary complications..$^{5-7}$ With CPAP, airway pressure is positive during the whole breathing cycle.

Ms Sehlin, Dr Sandkvist Törnell, Mr Johansson, and Dr Winsö are affiliated with the Department of Surgical and Perioperative Sciences, Anesthesiology and Intensive Care Medicine; and Dr Öhberg is affiliated with the Department of Radiation Sciences, Umeå University, Umeå, Sweden.

The study was supported by grants from Västerbotten County Council and the Medical Faculty of Umeå University.

The authors have disclosed no conflicts of interest.
Positive expiratory pressure can be achieved with a threshold resistor or a flow resistor. With a threshold resistor, the CPAP is obtained with a valve that opens and closes when the airway pressure is the same as the magnitude of the resistor. ${ }^{8,9}$ With a flow resistor, the CPAP is obtained with an opposing flow or an orifice resistor. ${ }^{9}$ With threshold resistor or flow resistor CPAP, to establish and maintain the positive pressure the equipment has to deliver an air flow that exceeds the peak air flow created by the patient,

\footnotetext{
Correspondence: Maria Sehlin RPT MSC, Department of Surgical and Perioperativ Sciences, Anesthesiology and Intensive Care Medicine, Umeå University Hospital, 90185 Umeå, Sweden. E-mail: maria.sehlin@ anestesi.umu.se.
}

DOI: $10.4187 /$ respcare.01015 


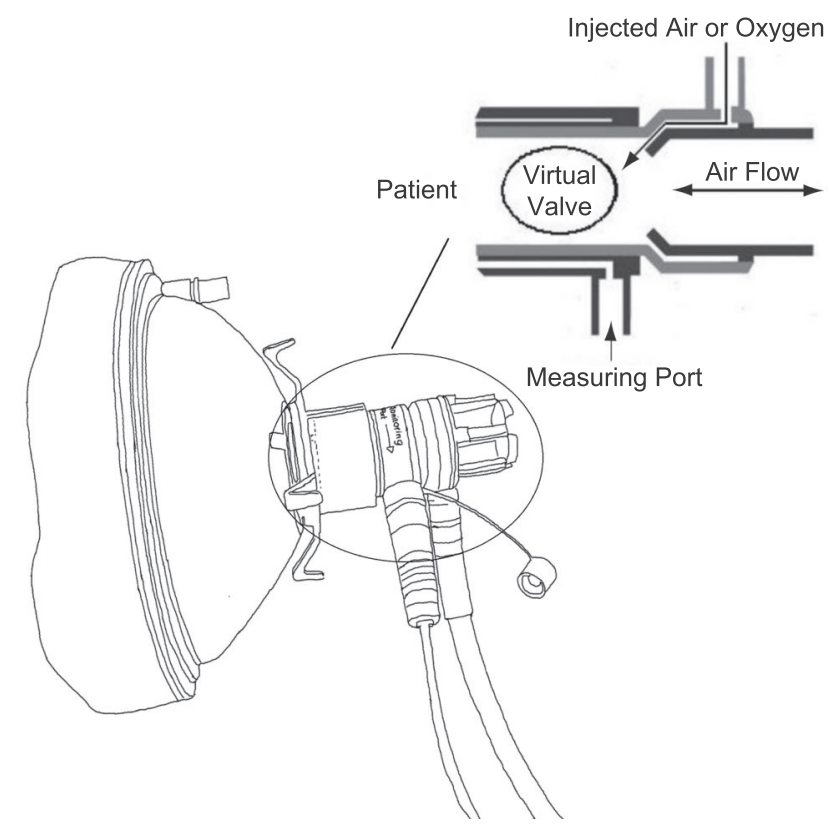

Fig. 1. The Boussignac continuous positive airway pressure system. Air or oxygen is injected through the micro-channels in the wall of the plastic tube. As the gas molecules accelerate through the channels and enter the cylinder a virtual valve is created.

during the whole breathing cycle. If pressure changes occur, respiratory work increases, which can lead to respiratory fatigue. ${ }^{10,11}$

The Boussignac CPAP system (Vygon, Écouen, France) includes a plastic tube (5.5-cm long, inner diameter $13 \mathrm{~mm}$ ) that has 4 micro-channels in the tube wall (Fig. 1). The tube is open to the atmosphere. With a flow meter, air or oxygen is injected into the micro-channels. When the delivered gas accelerates through the micro-channels, the gas molecules collide and turbulence occurs. The speed of the gas molecules is then transformed into pressure, thereby creating a virtual valve on the patient side of the tube. The speed of the gas flow through the micro-channels determines the CPAP level, which makes the pressure flow-dependent. The measurement port (see Fig. 1) allows pressure measurement or delivery of supplemental oxygen. , $3,12,13^{2}$

The Boussignac CPAP system is considered easy to use and it requires only a flow meter that delivers oxygen or air to create a continuous positive airway pressure. ${ }^{10,14,15}$ When oxygen is used, the amount of oxygen delivered to the patient and the CPAP level cannot be adjusted separately. ${ }^{16}$ If the measurement port is used to deliver supplementary oxygen, the possibility to monitor the CPAP level is lost.

In emergency departments and prehospital care, the Boussignac CPAP system effectively treats acute cardiogenic pulmonary edema $\mathrm{a}^{2,3,13,17}$ and treats or prevents postoperative complications in obese patients. ${ }^{7,14}$ In a recent bench study, Bellani and co-workers ${ }^{10}$ evaluated the Bous-

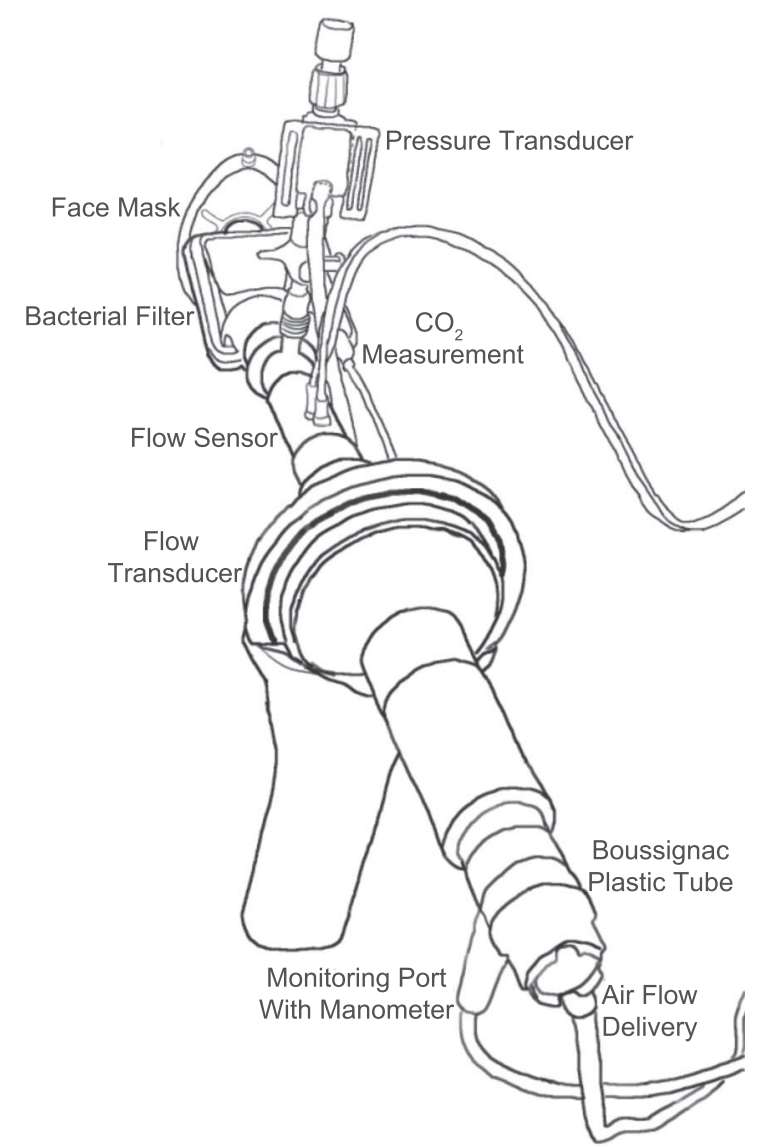

Fig. 2. Experimental setup.

signac CPAP system and observed that increased air flow was associated with enhanced airway pressure drop during inspiration. Those data indicate that the efficacy of the Boussignac CPAP system might be hampered during increased breathing efforts, which merits further investigation. We therefore studied the Boussignac CPAP system's ability to maintain stable inspiratory and expiratory pressure levels. We also evaluated perceived exertion during breathing with the Boussignac CPAP system.

\section{Methods}

This study was approved by the research ethics committee of Umeå University, and all the participants gave informed consent. We recruited 18 healthy volunteers: 13 women and 5 men, mean \pm SD age $44 \pm 8$ years. All the participants were non-smokers and, prior to study participation, underwent spirometry (vital capacity [VC] and $\mathrm{FEV}_{1}$ ) (model S, Vitalograph, Buckingham, United Kingdom) to ensure they had normal lung function. We used the best of 3 measurements for both $\mathrm{VC}$ and $\mathrm{FEV}_{1}$.

Figure 2 shows the setup, which includes a face mask (Boussignac, Vygon, Écouen, France), a bacterial filter 


\section{Pneumatic Performance of the Boussignac CPAP System in Healthy Humans}

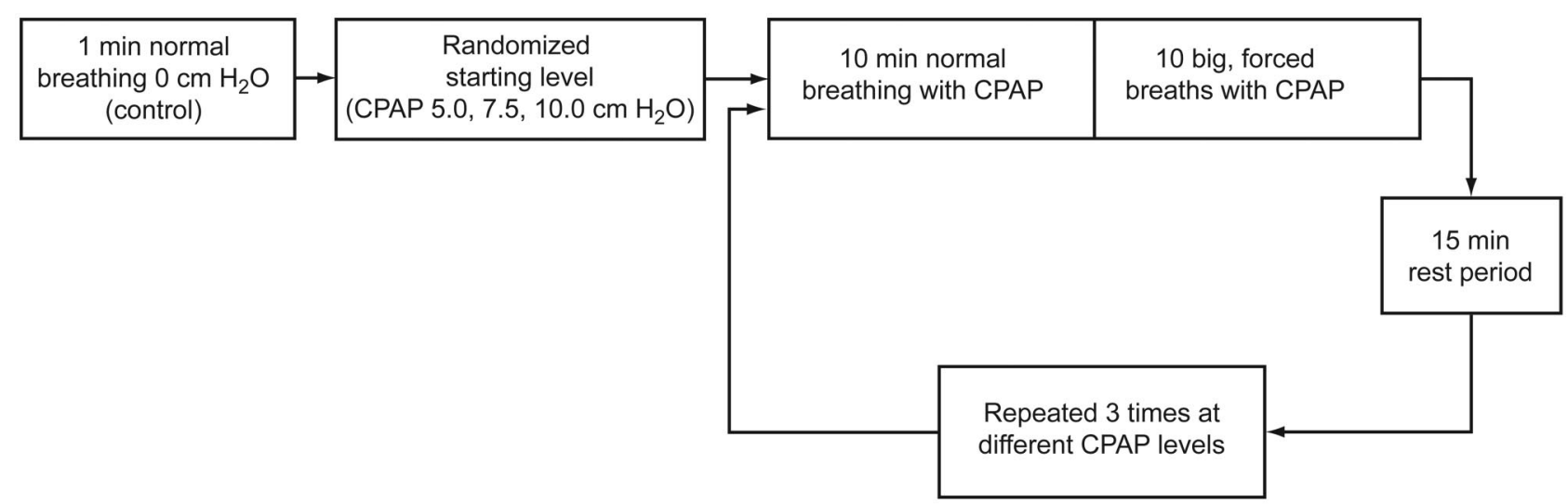

Fig. 3. Study protocol. CPAP $=$ continuous positive airway pressure.

(BaktPlus, Codan Triplus, Kungsbacka, Sweden), a pressure transducer (PMSET 1TNF-R, Beckton Dickinson, Singapore), a flow sensor (Marquette Medical Systems, Jupiter, Florida), an air-flow transducer (SS11LA, Biopac Systems, Goleta, California), the Boussignac plastic tube (5.5-cm long, inner diameter $13 \mathrm{~mm}$ ), and a flow meter to adjust the gas flow and thereby the CPAP level. A manometer (Vygon, Écouen, France) was connected to the monitoring port of the Boussignac plastic tube to measure the CPAP level. We measured end-tidal $\mathrm{CO}_{2}$ through a side port in the bacterial filter, and $\mathrm{S}_{\mathrm{pO}_{2}}$ (Marquette Medical Systems, Jupiter, Florida) via finger oximetry probe.

The participants sat on an adjustable chair in front of a table, with $90^{\circ}$ hips and knees flexion, feet firmly on the floor, elbows on the chair armrests, and the hands on the armrests or in the lap, except during the first measurement period (at $0 \mathrm{~cm} \mathrm{H}_{2} \mathrm{O}$ ), during which the participant's hands were placed on the CPAP mask. Before the CPAP breathing tests, each participant was instructed how to use the Borg category ratio 10 (Borg CR10) perceived exertion scale, ${ }^{18}$ and to breathe as normally as possible during CPAP (ie, to think as little as possible about how they were breathing).

Figure 3 shows the study protocol. We tested 4 CPAP levels: 0 (control), 5.0, 7.5, and $10.0 \mathrm{~cm} \mathrm{H}_{2} \mathrm{O}$. The measurement sequence always started with 0 CPAP for $1 \mathrm{~min}$, after which the participant scored his or her perceived exertion on the Borg CR10 scale. ${ }^{18}$ Then, in randomized order, the participant breathed at each CPAP level for $10 \mathrm{~min}$. Each 10-min session ended with 10 forced breaths (as if running), to simulate respiratory distress, and holding the last exhalation for a couple of seconds. The participant scored his or her perceived exertion just before the 10 forced breaths. ${ }^{18}$ The participants were blinded to the order of the CPAP levels. To avoid carryover effects, the participant rested for 15 min between each CPAP level.

During CPAP breathing airway pressure and air flow were continuously recorded, at $200 \mathrm{~Hz}$, with data-acqui- sition software (Biopac Student Lab Pro 3.7.1, Biopac Systems, Goleta, California). We continuously recorded $\mathrm{S}_{\mathrm{pO}_{2}}$, heart rate (via pulse oximeter) and end-tidal $\mathrm{CO}_{2}$ at $0.5 \mathrm{~Hz}$, with custom-made data-acquisition software (MRDView 2.4.2.6). We titrated air flow to the desired CPAP level with a manometer, and no adjustments of delivered air flow were made once the recording had started. Figure 4 shows a typical recording of airway pressure and air flow from one subject.

\section{Calibrations}

We calibrated the equipment as described previously. ${ }^{19}$ Before the tests we calibrated the pressure transducer with a water column at 0 and $10 \mathrm{~cm} \mathrm{H}_{2} \mathrm{O}$. The air-flow transducer was calibrated with a $600-\mathrm{mL}$ syringe before and after every participant. We measured the air flow and air pressure signals during a period of no air flow, and any offset in the signal was subtracted from the recorded signal during CPAP testing. The other sensors were calibrated by the manufacturer.

To eliminate high-frequency noise we filtered the recorded air flow and airway pressure signals with a numerical finite-impulse-response low-pass filter with a cutoff frequency of $10 \mathrm{~Hz},{ }^{20,21}$ implemented with a Hanning window with 39 coefficients.

\section{Analysis}

Analysis of the air flow and airway pressure recordings were done manually. For the 1-min recording at $0 \mathrm{~cm} \mathrm{H}_{2} \mathrm{O}$, we analyzed 10 breaths. For the 10-min recordings, we analyzed 10 breaths from the beginning, 10 from the middle, and 10 from the end of each 10 min period. Of the 10 forced breaths, we analyzed the first 9 breaths. The shift between inspiration and expiration was defined as the point where the air flow signal passed zero L/s (ie, when the air-flow signal changed from positive [inspiration] to neg- 


\section{Pneumatic Performance of the Boussignac CPAP System in Healthy Humans}

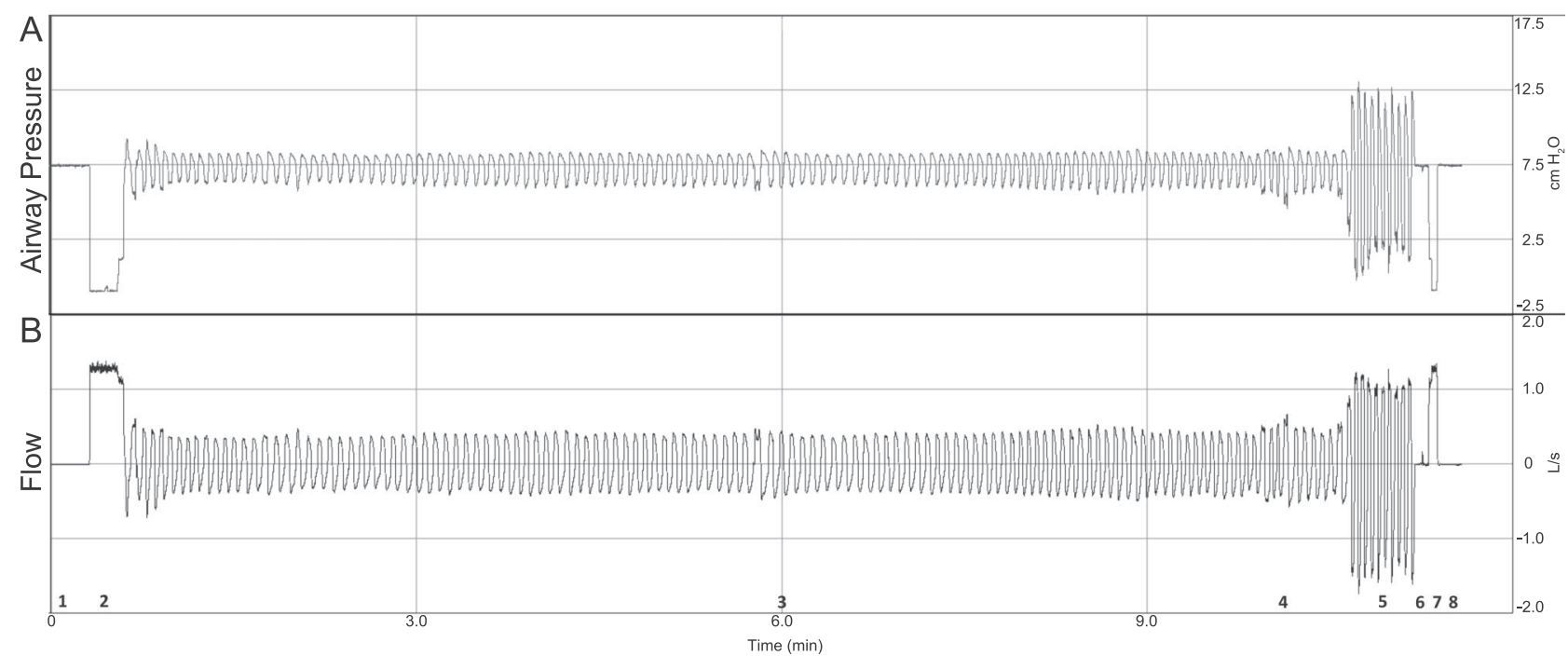

Fig. 4. Typical wave forms of airway pressure (A) and air flow (B). After titrating the air flow to the desired continuous positive airway pressure (CPAP), the recording was started (1) and the CPAP mask was connected with a head-strap to the participant (2). After 10 min of CPAP breathing (3) the participant scored his or her perceived exertion (4), then took 10 forced breaths (5), and held the last exhalation for a couple of seconds (6). Then the mask was removed (7), and the recording was stopped (8) and the CPAP turned off.

ative [expiration] or vice versa). For $\mathrm{S}_{\mathrm{pO}_{2}}$, heart rate, and end-tidal $\mathrm{CO}_{2}$ we analyzed the last 5 sampled values from the 1-min recordings, the 10-min recordings, and the forced breathing period.

\section{Statistical Analysis}

We used repeated-measures analysis of variance to compare the CPAP levels. When the Mauchly test indicated that the assumption of sphericity had been violated, we applied the Greenhouse-Geisser correction. We used the Bonferroni correction as a post hoc test. For each CPAP level, we compared the normal-breathing data and the forced-breathing data with the paired $t$ test. $P<.05$ was considered statistically significant. Data are presented as mean $\pm \mathrm{SD}$, except for the Borg CR10 scores, which are reported as median and range values. Data analysis was with statistics software (SPSS 18.0, SPSS, Chicago, Illinois).

\section{Results}

One of our participants interrupted the $10 \mathrm{~cm} \mathrm{H}_{2} \mathrm{O}$ trial after a couple of minutes, due to severe respiratory fatigue, but completed the trials at the other CPAP levels. Due to a drift in the air-flow signal at $10 \mathrm{~cm} \mathrm{H}_{2} \mathrm{O}$, we excluded data from another participant, which reduced the number of $10 \mathrm{~cm} \mathrm{H}_{2} \mathrm{O}$ periods to 16 . Data are also missing for $\mathrm{S}_{\mathrm{pO}_{2}}$, heart rate, and end-tidal measurements at $0 \mathrm{~cm} \mathrm{H} \mathrm{H}_{2} \mathrm{O}$ (control) for one subject, due to recording problems. With another subject we failed to obtain data during the forced breaths in the $5 \mathrm{~cm} \mathrm{H}_{2} \mathrm{O}$ session. The $0 \mathrm{~cm} \mathrm{H}_{2} \mathrm{O}$ (control) Borg CR10 score was not recorded with one participant.

\section{Demographics}

Our 18 participants were $171 \pm 8 \mathrm{~cm}$ tall and weighed $77 \pm 12 \mathrm{~kg}$. Their pulmonary function was normal: VC $4.22 \pm 0.97 \mathrm{~L} \quad(92-127 \%$ of predicted), $\mathrm{FEV}_{1} 3.40 \pm 0.72 \mathrm{~L}$ (84-127\% of predicted). $\mathrm{S}_{\mathrm{pO}_{2}}$ was 97-98\% during all measurements. Heart rate was $70 \pm 9$ beats/min at CPAP of $0 \mathrm{~cm} \mathrm{H}_{2} \mathrm{O}$. At CPAP of 5.0, 7.5 , and $10.0 \mathrm{~cm} \mathrm{H}_{2} \mathrm{O}$, respectively, heart rate was $75 \pm 8$ beats $/ \mathrm{min}(P<.001), 74 \pm 11$ beats $/ \min (P=.006)$, and $76 \pm 12$ beats/min $(P<.001)$ during normal breathing, and $78 \pm 9$ beats $/ \mathrm{min}(P<.001), 81 \pm 15$ beats $/ \mathrm{min}$ $(P=.001)$, and $82 \pm 14$ beats/min $(P<.001)$ during forced breathing.

\section{Changes in Airway Pressure}

During inspiration, airway pressure decreased (Fig. 5). The pressure drop was larger at all CPAP levels, during both normal and forced breathing, than during 0 CPAP (control). During normal breathing, as the CPAP level increased, the decrease in airway pressure was enhanced. At a given CPAP level, airway pressure was lower during forced breaths than during normal breathing.

Figure 6 shows the maximum and mean airway pressure increases during expiration. Both the maximum 

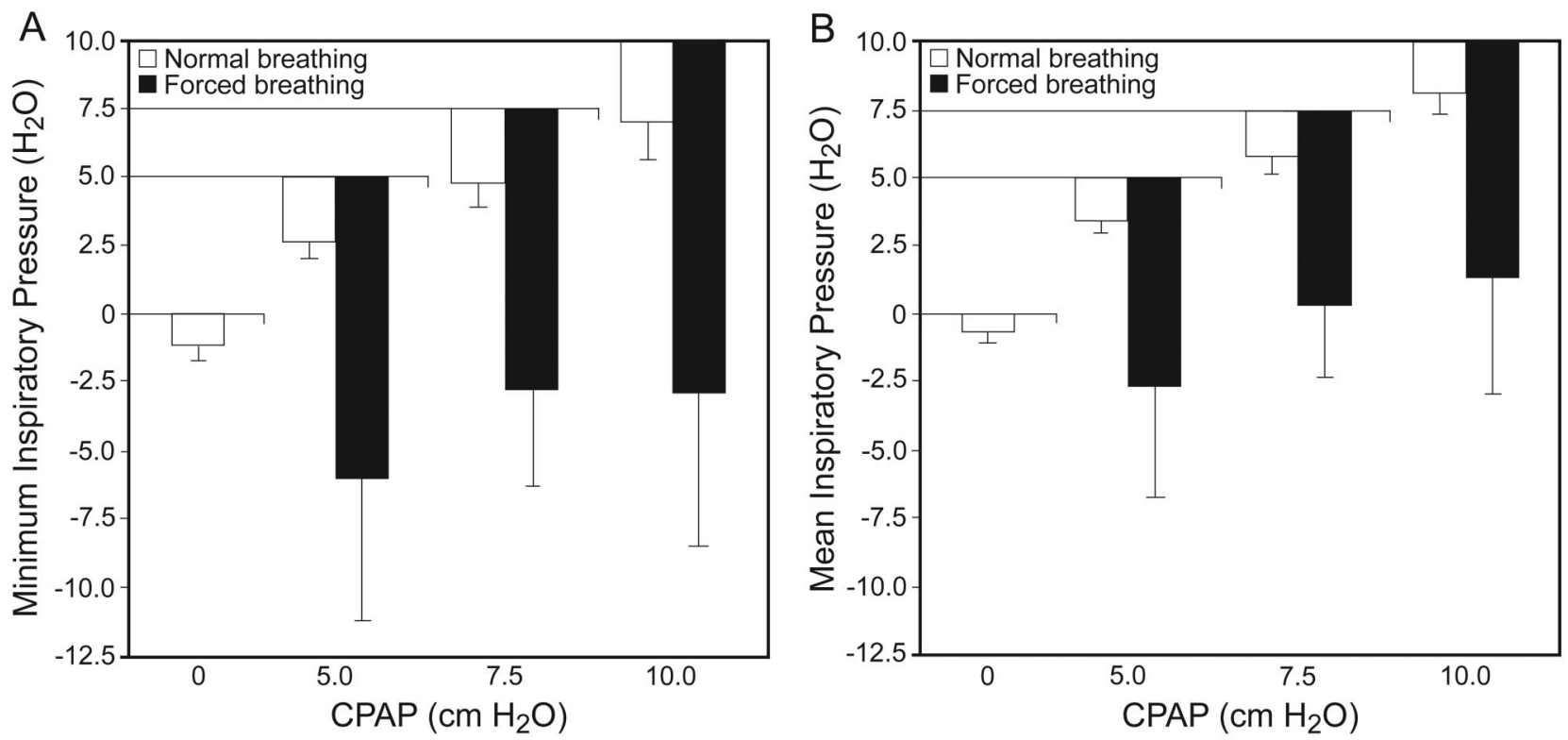

Fig. 5. A: Minimum inspiratory airway pressure at 4 continuous positive airway pressure (CPAP) levels, during normal breathing and forced breathing. $P<.001$ for control versus normal breathing and forced breathing, at all CPAP levels. $P=.006$ for normal breathing at CPAP of $5 \mathrm{~cm} \mathrm{H} \mathrm{H}_{2} \mathrm{O}$ versus $7.5 \mathrm{~cm} \mathrm{H} \mathrm{H}_{2} \mathrm{O} . P=.006$ for forced breathing at CPAP of $7.5 \mathrm{~cm} \mathrm{H}_{2} \mathrm{O}$ versus $10 \mathrm{~cm} \mathrm{H}_{2} \mathrm{O}$. $P<.001$ for normal breathing versus forced breathing at the corresponding CPAP levels. B: Mean inspiratory airway pressure. $P<.001$ for control versus normal breathing and forced breathing, at all CPAP levels. $P=.01$ for normal breathing at CPAP of $5 \mathrm{~cm} \mathrm{H}_{2} \mathrm{O}$ versus $7.5 \mathrm{~cm} \mathrm{H}_{2} \mathrm{O}$. $P<.02$ for forced breathing at CPAP of $7.5 \mathrm{~cm} \mathrm{H}_{2} \mathrm{O}$ versus $10 \mathrm{~cm} \mathrm{H}_{2} \mathrm{O} . P<.001$ for normal breathing versus forced breathing at the corresponding CPAP levels.
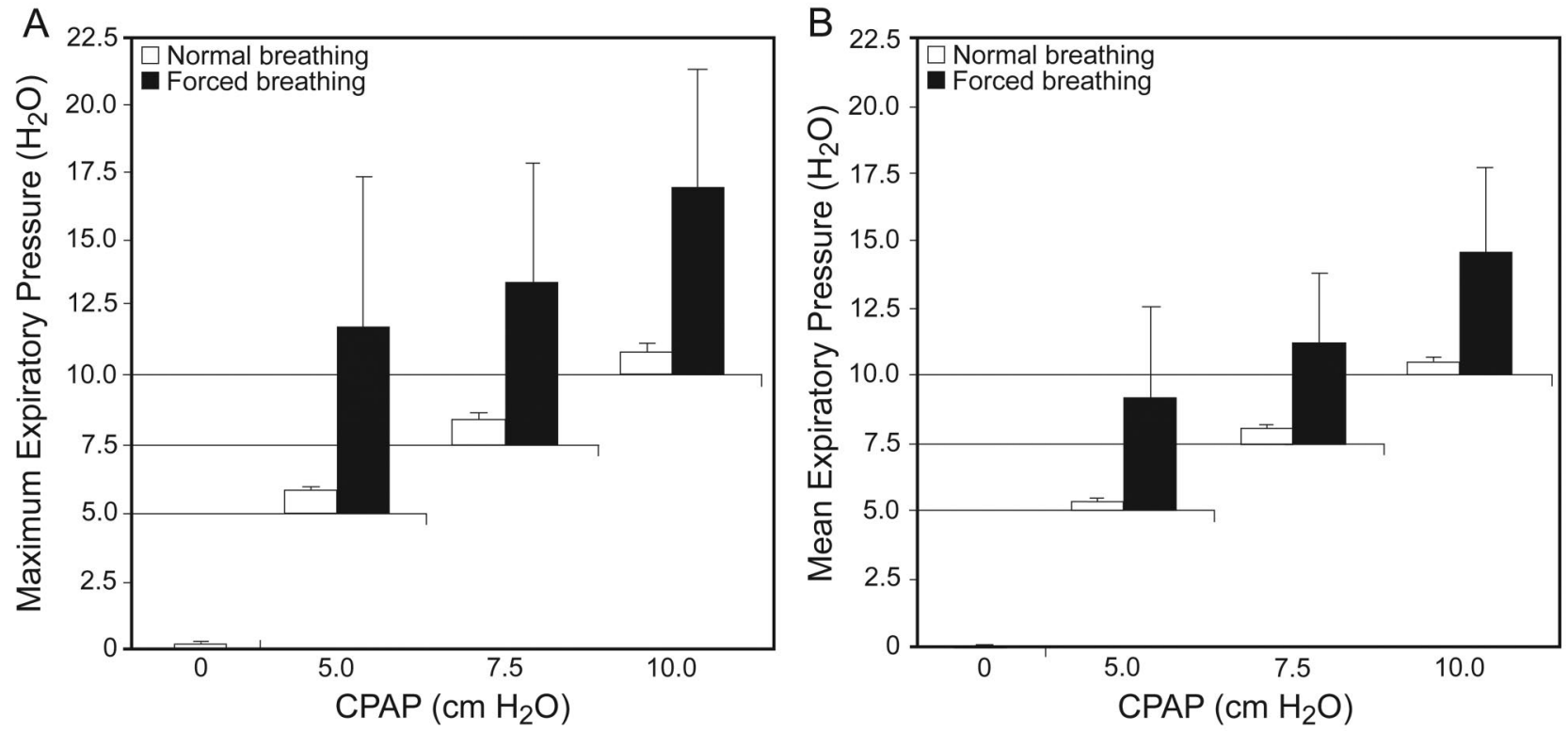

Fig. 6. A: Maximum expiratory airway pressure at 4 continuous positive airway pressure (CPAP) levels, during normal breathing and forced breathing. $P<.001$ for control versus normal breathing and forced breathing, at all CPAP levels. $P<.001$ for normal breathing at CPAP of $5 \mathrm{~cm} \mathrm{H}_{2} \mathrm{O}$ versus $7.5 \mathrm{~cm} \mathrm{H}_{2} \mathrm{O}$, and $P=.026$ for CPAP of $7.5 \mathrm{~cm} \mathrm{H}_{2} \mathrm{O}$ versus $10 \mathrm{~cm} \mathrm{H}_{2} \mathrm{O} . P<.001$ for normal breathing versus forced breathing at the corresponding CPAP levels. B: Mean expiratory airway pressure. $P<.001$ for control versus normal breathing and forced breathing, at all CPAP levels. $P<.001$ for normal breathing at CPAP of $5 \mathrm{~cm} \mathrm{H}_{2} \mathrm{O}$ versus $7.5 \mathrm{~cm} \mathrm{H}_{2} \mathrm{O}$, and for CPAP of $7.5 \mathrm{~cm} \mathrm{H}_{2} \mathrm{O}$ versus $10 \mathrm{~cm} \mathrm{H}_{2} \mathrm{O}$. $P<.001$ for normal breathing versus forced breathing at the corresponding CPAP levels.

and mean airway pressure was slightly higher during CPAP of 5.0, 7.5, and $10.0 \mathrm{~cm} \mathrm{H}_{2} \mathrm{O}$ than during control normal breathing. Airway pressure increased with increasing CPAP. The airway pressure increase was higher 

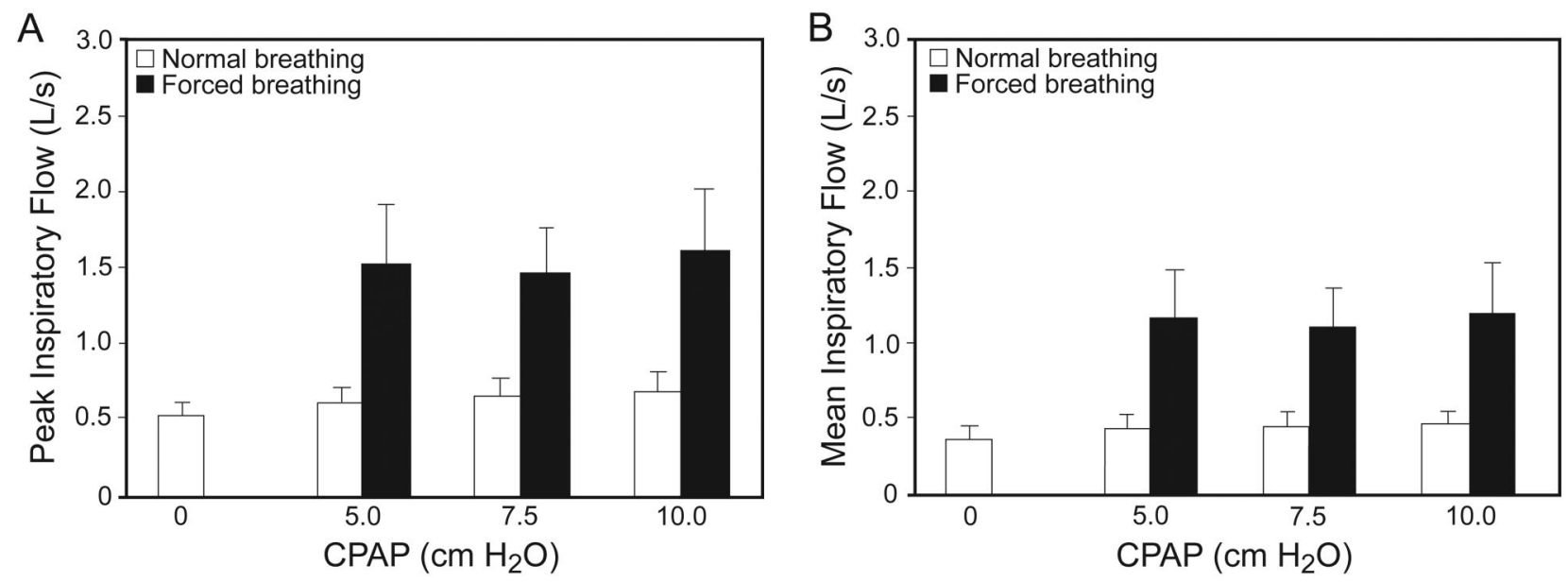

Fig. 7. A: Peak inspiratory air flow at 4 continuous positive airway pressure (CPAP) levels, during normal breathing and forced breathing. $P=.02$ for control versus normal breathing at CPAP of $5 \mathrm{~cm} \mathrm{H}_{2} \mathrm{O} . P=.003$ for control versus normal breathing at CPAP of $7.5 \mathrm{~cm} \mathrm{H}_{2} \mathrm{O}$. $P=.001$ for control versus normal breathing at CPAP of $10 \mathrm{~cm} \mathrm{H}_{2} \mathrm{O} . P<.001$ for control versus forced breathing, at all CPAP levels. $P<.001$ for normal breathing versus forced breathing at the corresponding CPAP levels. B: Mean inspiratory air flow. $P=.045$ for control versus normal breathing at CPAP of $5 \mathrm{~cm} \mathrm{H}_{2} \mathrm{O} . P=.03$ for control versus normal breathing at CPAP of $7.5 \mathrm{~cm} \mathrm{H}_{2} \mathrm{O} . P=.004$ for control versus normal breathing at $10 \mathrm{~cm} \mathrm{H}_{2} \mathrm{O} . P<.001$ for control versus forced breathing, at all CPAP levels. $P<.001$ for normal breathing versus forced breathing at the corresponding CPAP levels.
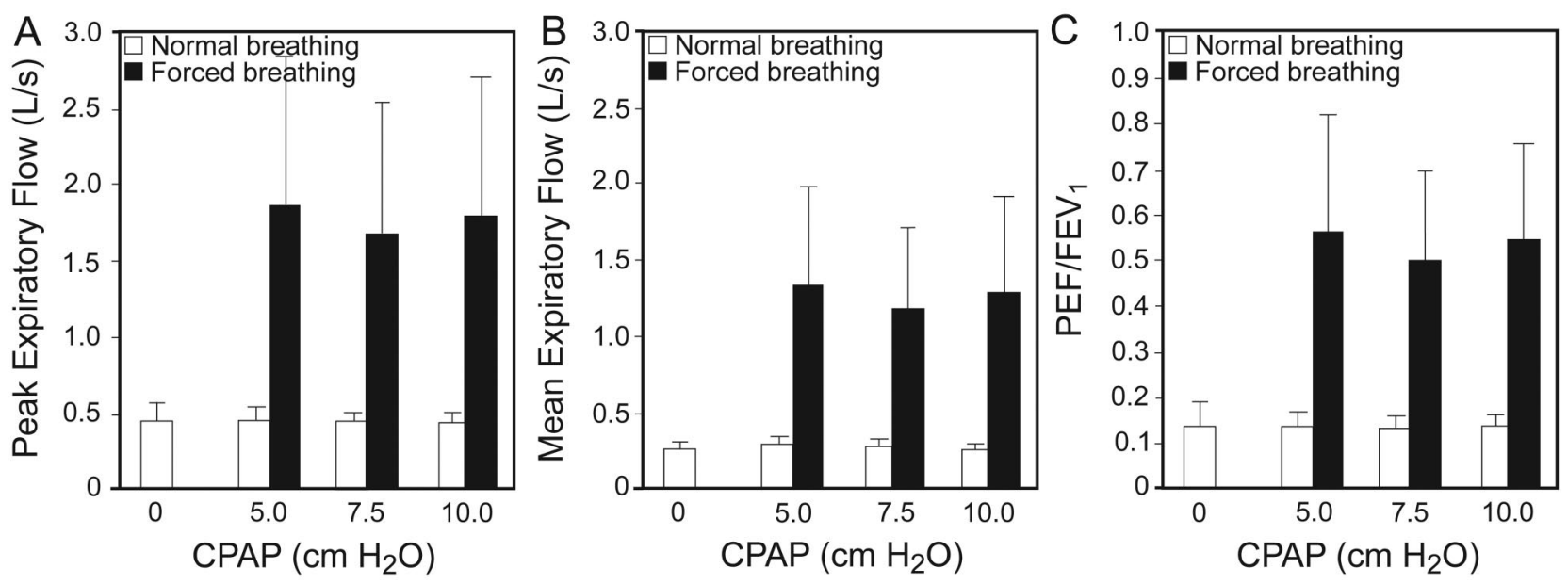

Fig. 8. A: Peak expiratory flow at 4 continuous positive airway pressure (CPAP) levels, during normal breathing and forced breathing. $P<.001$ for control versus forced breathing, at all CPAP levels, and for normal breathing versus forced breathing at the corresponding CPAP levels. B: Mean expiratory flow. $P<.001$ for control versus forced breathing, at all CPAP levels, and for normal breathing versus forced breathing at the corresponding CPAP levels. C: Ratio of peak expiratory flow to FEV $1 . P<.001$ for control versus forced breathing, at all CPAP levels, and for normal breathing versus forced breathing at the corresponding CPAP levels.

during forced breathing than during control normal breathing or normal breathing at that CPAP level.

\section{Changes in Air Flow}

Figures 7 and 8 show the peak and mean inspiratory and expiratory flows, respectively. Figure 8 also shows the ratio of peak expiratory flow to $\mathrm{FEV}_{1}$. Both the peak and mean inspiratory and expiratory flows were higher during forced breathing than during breathing normally at the corresponding CPAP levels. The peak and mean inspiratory and expiratory flows were higher during normal and forced CPAP breathing than during control normal breathing. During normal breathing, peak expiratory flow was $14 \%$ of $\mathrm{FEV}_{1}$, irrespective of the CPAP level. During forced breathing, peak expiratory flow was $49-56 \%$ of $\mathrm{FEV}_{1}$. 
Pneumatic Performance of the Boussignac CPAP System in Healthy Humans

Table 1. Inspiratory Time, Expiratory Time, Respiratory Rate, Breathing Pattern, and End-Tidal $\mathrm{CO}_{2}$

\begin{tabular}{|c|c|c|c|c|c|c|c|}
\hline \multirow[b]{2}{*}{$\mathrm{CPAP}\left(\mathrm{cm} \mathrm{H}_{2} \mathrm{O}\right)$} & \multicolumn{4}{|c|}{ Normal Breathing } & \multicolumn{3}{|c|}{ Forced Breathing } \\
\hline & 0 & 5.0 & 7.5 & 10.0 & 5.0 & 7.5 & 10.0 \\
\hline Inspiratory time (s) & $2.0 \pm 0.5$ & $1.9 \pm 0.4$ & $1.9 \pm 0.4$ & $1.9 \pm 0.4$ & $1.4 \pm 0.5$ & $1.4 \pm 0.5$ & $1.6 \pm 0.9$ \\
\hline$P$ vs control breathing & NA & NS & NS & NS & .004 & .001 & .08 \\
\hline $\begin{array}{l}P \text { normal vs forced breathing, at } \\
\text { corresponding CPAP level }\end{array}$ & NA & NA & NA & NA & .01 & .001 & .25 \\
\hline Expiratory time (s) & $2.8 \pm 0.5$ & $2.7 \pm 0.7$ & $2.9 \pm 0.6$ & $3.0 \pm 0.8$ & $1.5 \pm 0.7$ & $1.5 \pm 0.7$ & $1.7 \pm 1.0$ \\
\hline$P$ vs control breathing & NA & NS & NS & NS & $<.001$ & $<.001$ & .001 \\
\hline $\begin{array}{l}P \text { normal vs forced breathing, at } \\
\text { corresponding CPAP level }\end{array}$ & NA & NA & NA & NA & $<.001$ & $<.001$ & .002 \\
\hline Respiratory rate (breaths/min) & 12 & 13 & 12 & 12 & 21 & 21 & 19 \\
\hline End-tidal $\mathrm{CO}_{2}(\mathrm{~mm} \mathrm{Hg})$ & $39 \pm 2$ & $36 \pm 3$ & $36 \pm 3$ & $35 \pm 3$ & $26 \pm 3$ & $26 \pm 3$ & $25 \pm 3$ \\
\hline$P$ vs control breathing & NA & .003 & .002 & .002 & $<.001$ & $<.001$ & $<.001$ \\
\hline $\begin{array}{l}P \text { normal vs forced breathing, at } \\
\text { corresponding CPAP level }\end{array}$ & NA & NA & NA & NA & $<.001$ & $<.001$ & $<.001$ \\
\hline Exhaled volume (L) & $0.72 \pm 0.19$ & $0.78 \pm 0.12$ & $0.81 \pm 0.12$ & $0.80 \pm 0.15$ & $1.57 \pm 0.48$ & $1.54 \pm 0.63$ & $1.72 \pm 0.62$ \\
\hline$P$ vs control breathing & NA & NS & NS & NS & $<.001$ & $<.001$ & $<.001$ \\
\hline $\begin{array}{l}P \text { normal vs forced breathing, at } \\
\text { corresponding CPAP level }\end{array}$ & NA & NA & NA & NA & $<.001$ & $<.001$ & $<.001$ \\
\hline $\begin{array}{l} \pm \text { values are mean } \pm \text { SD. } \\
\text { CPAP }=\text { continuous positive airway pressure } \\
\mathrm{NA}=\text { not applicable } \\
\mathrm{NS}=\text { not significant }\end{array}$ & & & & & & & \\
\hline
\end{tabular}
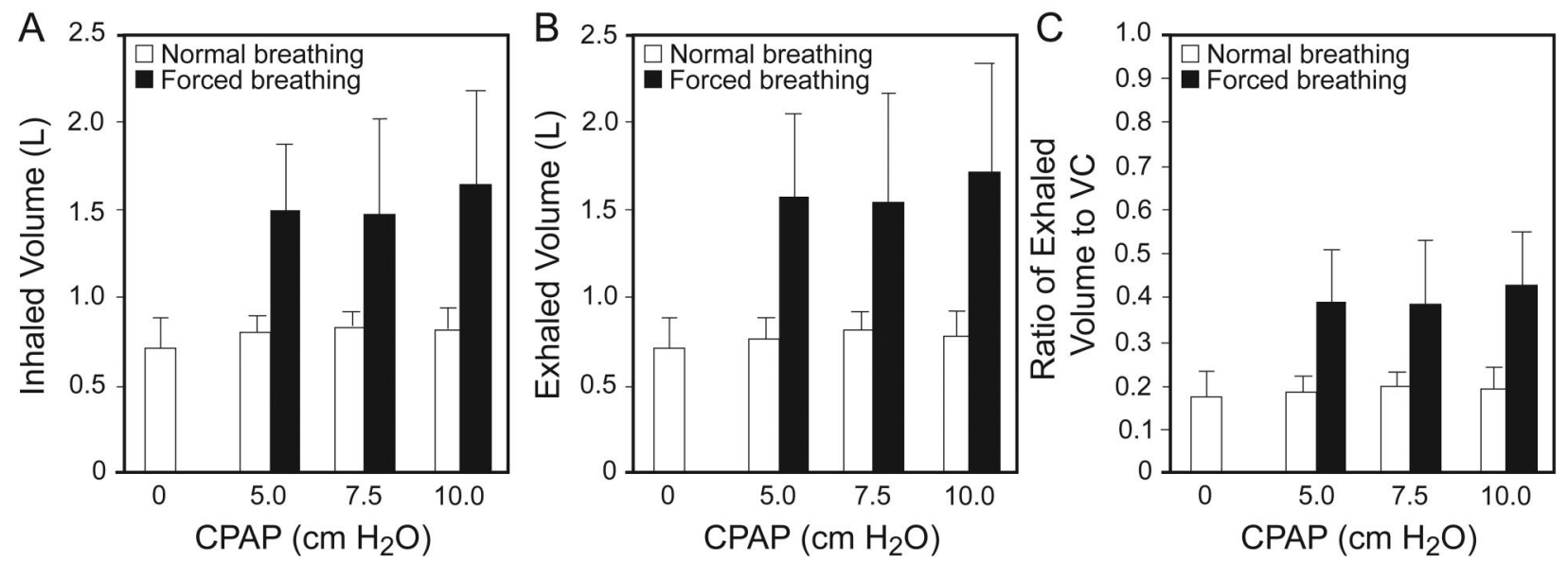

Fig. 9. A: Inhaled volume per breath at 4 continuous positive airway pressure (CPAP) levels, during normal breathing and forced breathing. $P<.001$ for control versus forced breathing, at all CPAP levels, and for normal breathing versus forced breathing at the corresponding CPAP levels. B: Exhaled volume per breath. $P<.001$ for control versus forced breathing, at all CPAP levels, and for normal breathing versus forced breathing at the corresponding CPAP levels. C: Ratio of exhaled volume to vital capacity (VC). $P<.001$ for control versus forced breathing, at all CPAP levels, and for normal breathing versus forced breathing at the corresponding CPAP levels.

\section{Breathing Pattern}

Table 1 shows the inspiratory and expiratory time, respiratory rate, and end-tidal $\mathrm{CO}_{2}$ data. Both inspiratory and expiratory time were longer, at all CPAP levels, during normal breathing than during forced breathing. During normal breathing end-tidal $\mathrm{CO}_{2}$ decreased slightly with increasing CPAP level.
Figure 9 shows the inhaled volume, exhaled volume, and ratio of exhaled volume to $\mathrm{VC}$ data. Both the inhaled and exhaled volumes were higher during forced breathing than during normal breathing, at all CPAP levels. There were no volume differences between the normal breaths or between the forced breaths at any CPAP level. When breathing normally, at all 4 CPAP levels, tidal volume was $20 \%$ of VC. During the forced 


\section{Pneumatic Performance of the Boussignac CPAP System in Healthy Humans}

breaths the participants breathed at $38-42 \%$ of their VCs.

\section{Perceived Exertion}

The median Borg CR10 scores were 0.7 (range 0-2.5) at $0 \mathrm{~cm} \mathrm{H}_{2} \mathrm{O}, 1$ (range 0-3) at $5 \mathrm{~cm} \mathrm{H}_{2} \mathrm{O}, 2$ (range 0-7) at $7.5 \mathrm{~cm} \mathrm{H}_{2} \mathrm{O}$, and 2.5 (range 1-7) at $10 \mathrm{~cm} \mathrm{H}_{2} \mathrm{O}$. The participant who interrupted breathing at $10 \mathrm{~cm} \mathrm{H}_{2} \mathrm{O}$ scored the perceived exertion at 7 .

\section{Discussion}

During 10-min normal breathing periods, when the participants breathed at $20 \%$ of $\mathrm{VC}$, with a peak expiratory flow of $14 \%$ of $\mathrm{FEV}_{1}$, airway pressure decreased during inspiration and increased slightly during expiration. However, the airway pressure changes were never large enough to reduce airway pressure to below zero, indicating that the Boussignac CPAP system functioned well during normal breathing. However, pressure changes did occur during normal breathing, and these changes increased with increasing CPAP.

During forced breathing, expiratory volume was $38-$ $42 \%$ of VC and peak expiratory flow was $49-56 \%$ of $\mathrm{FEV}_{1}$. During forced breaths, as air flow increased, both the drop in inspiratory airway pressure and the increase in expiratory airway pressure were more pronounced. The magnitude of these pressure changes was $10-12 \mathrm{~cm} \mathrm{H}_{2} \mathrm{O}$, resulting in negative airway pressure during inspiration. During expiration, the maximum airway pressure range was $11-16 \mathrm{~cm} \mathrm{H}_{2} \mathrm{O}$ at $5-10 \mathrm{~cm} \mathrm{H}_{2} \mathrm{O}$.

Pressure changes during breathing with CPAP are associated with increased work of breathing, ${ }^{10,11,22}$ and it is therefore important that airway pressure is stable during the whole breathing cycle. When a patient's inspiratory air flow exceeds the air flow delivered by the CPAP equipment, airway pressure will fall, which will increase respiratory work and possibly lead to fatigue. ${ }^{10,11,22}$ Though the Borg CR10 scale is subjective and not a pressure-related measure of WOB, the perceived exertion scores from our subjects were quite low for all CPAP levels. Inter-individual differences in perceived exertion increased at higher CPAP levels. One of our participants interrupted the $10 \mathrm{~cm} \mathrm{H}_{2} \mathrm{O}$ trial due to severe respiratory distress and scored that perceived exertion at 7 . We did not measure perceived exertion during forced breathing. The discrepancy between the positive findings obtained in some clinical studies and our observation of inadequate pneumatic performance of the Boussignac CPAP system during forced breathing and the perceived exertion in association with CPAP breathing raises doubts about the clinical relevance of these experimental findings. Thus, further physiological studies in patients with acute respiratory distress are war- ranted. Such studies should focus on the effective consequences of the observed pneumatic instability of the Boussignac CPAP system during forced breathing when used by patients with increased ventilatory needs.

In a bench study of 4 different Boussignac CPAP systems (one unmodified system and 3 modified systems), Bellani and co-workers ${ }^{10}$ reported on pressure changes and oxygen concentrations during CPAP breathing. Pressure drop during inspiration correlated to increased air flow. In their model, during expiration, with increased air flow and consequent increased tidal volume, airway pressure increases were enhanced during expiration. Thus, similar to our observations, caution is necessary when air flow is enhanced.

Except for the present study and the study by Bellani and co-workers, ${ }^{10}$ we are only aware of one other study on airway pressure with the Boussignac CPAP system. ${ }^{13}$ The main focus of that study was the applicability of the system in prehospital care of patients with acute pulmonary edema. Those authors reported on differences between inspiratory and expiratory pressures. Similar to our data, and data from Bellani and co-workers, ${ }^{10}$ they reported greater pressure differences at higher CPAP levels. ${ }^{13}$ None of the other studies we know of (see the Introduction section above) focused on airway pressure.

Some methodological aspects have to be discussed. First, we chose CPAP levels of 5.0, 7.5, and $10.0 \mathrm{~cm} \mathrm{H}_{2} \mathrm{O}$ in concordance with CPAP levels most often used in everyday clinical practice. In our experience, at higher CPAP levels, the risk of air leak around the face mask is increased. With CPAP higher than $10 \mathrm{~cm}$ of $\mathrm{H}_{2} \mathrm{O}$ it is almost impossible to avoid air leak, so we chose $10 \mathrm{~cm} \mathrm{H}_{2} \mathrm{O}$ as the highest CPAP. Further, air leak is an obstacle to accurate measurement, and with one participant the data from the $10 \mathrm{~cm} \mathrm{H}_{2} \mathrm{O}$ session had to be omitted for this reason. One could argue that the progressive impairment of the pneumatic performance of the Boussignac system at higher CPAP is due to increased mask leak, but it was not possible to evaluate the impact of air leaks on the observed changes in airway pressure under the increasing CPAP levels, so a bench study may have better addressed this phenomenon.

Second, we evaluated both normal and forced breathing. The at-rest flow is reported to be $20-30 \mathrm{~L} / \mathrm{min}$, and in respiratory failure flow over $100 \mathrm{~L} / \mathrm{min}$ is often seen. ${ }^{11}$ To simulate respiratory distress, our participants took 10 deep, forced breaths, and had flows of $88-97 \mathrm{~L} / \mathrm{min}$, which is consistent with flows reported during respiratory distress. ${ }^{11}$ Our instructions to the participants on how to perform the forced breaths can be questioned. Various participants responded very differently to the instructions, with very different breathing patterns. However, all the participants received identical instructions, read from a written instruction sheet. It could be argued that the participants also should 


\section{Pneumatic Performance of the Boussignac CPAP System in Healthy Humans}

have performed forced breaths at the control CPAP level $\left(0 \mathrm{~cm} \mathrm{H}_{2} \mathrm{O}\right.$ ), but our aim was to test the Boussignac system during CPAP breathing with air flows similar to respiratory distress: not to measure air flows during forced breathing without CPAP.

Third, since we used healthy volunteers the air flow and volumes could not be standardized, as in a bench study, which made it impractical to report exact pressures during specific air flows. We did not measure blood pressure, so we collected no data on the potential impact of CPAP on cardiovascular variables.

Fourth, we used a different filter for the air flow and airway pressure signals than did Barbini and co-workers ${ }^{20}$ or Avanzolini and co-workers, ${ }^{21}$ but we do not think that the small differences in cut-off frequency $(3 \mathrm{~Hz})$ or filter type (ie, Hanning instead of Hamming window) affected our results.

\section{Conclusions}

Based on our findings, and the results from Bellani and co-workers, ${ }^{10}$ we conclude that the pneumatic performance of the Boussignac CPAP system is adequate during normal breathing with low air flow, but during forced breathing and high air flow the Boussignac CPAP system is unable to maintain stable airway pressure, which could increase the work of breathing and cause respiratory fatigue. Thus, the Boussignac CPAP system might be less suitable for patients breathing at a higher frequency.

\section{REFERENCES}

1. Peter JV, Moran JL, Phillips-Hughes J, Graham P, Bersten AD. Effect of non-invasive positive pressure ventilation (NIPPV) on mortality in patients with acute cardiogenic pulmonary oedema: a metaanalysis. Lancet 2006;367(9517):1155-1163.

2. Leman P, Greene S, Whelan K, Legassick T. Simple lightweight disposable continuous positive airways pressure mask to effectively treat acute pulmonary oedema: randomized controlled trial. Emerg Med Australas 2005;17(3):224-230.

3. Moritz F, Benichou J, Vanheste M, Richard JC, Line S, Hellot MF, et al. Boussignac continuous positive airway pressure device in the emergency care of acute cardiogenic pulmonary oedema: a randomized pilot study. Eur J Emerg Med 2003;10(3):204-208.

4. Giles TL, Lasserson TJ, Smith BH, White J, Wright J, Cates CJ. Continuous positive airways pressure for obstructive sleep apnoea in adults. Cochrane Database Syst Rev 2006;(3):CD001106.

5. Squadrone V, Coha M, Cerutti E, Schellino MM, Biolino P, Occella $\mathrm{P}$, et al. Continuous positive airway pressure for treatment of postoperative hypoxemia: a randomized controlled trial. JAMA 2005; 293(5):589-595.

6. Fagevik Olsen M, Wennberg E, Johnsson E, Josefson K, Lonroth H, Lundell L. Randomized clinical study of the prevention of pulmo- nary complications after thoracoabdominal resection by two different breathing techniques. Br J Surg 2002;89(10):1228-1234.

7. Neligan PJ, Malhotra G, Fraser M, Williams N, Greenblatt EP, Cereda $\mathrm{M}$, et al. Continuous positive airway pressure via the Boussignac system immediately after extubation improves lung function in morbidly obese patients with obstructive sleep apnea undergoing laparoscopic bariatric surgery. Anesthesiology 2009;110(4):878-884.

8. Banner MJ, Lampotang S, Boysen PG, Hurd TE, Desautels DA. Flow resistance of expiratory positive-pressure valve systems. Chest 1986;90(2):212-217.

9. Kacmarek RM, Dimas S, Reynolds J, Shapiro BA. Technical aspects of positive end-expiratory pressure (PEEP): Part I. Physics of PEEP devices. Respir Care 1982;27(12):1478-1489.

10. Bellani G, Foti G, Spagnolli E, Castagna L, Patroniti N, Pesenti A. An improved Boussignac device for the delivery of non-invasive CPAP: the SUPER-Boussignac. Intensive Care Med 2009;35(6): 1094-1099.

11. Glover GW, Fletcher SJ. Assessing the performance of the Whisperflow continuous positive airway pressure generator: a bench study. Br J Anaesth 2009;102(6):875-881.

12. Maitre B, Jaber S, Maggiore SM, Bergot E, Richard JC, Bakthiari H, et al. Continuous positive airway pressure during fiberoptic bronchoscopy in hypoxemic patients. A randomized double-blind study using a new device. Am J Respir Crit Care Med 2000;162(3 Pt 1):1063-1067.

13. Templier F, Dolveck F, Baer M, Chauvin M, Fletcher D. 'Boussignac' continuous positive airway pressure system: practical use in a prehospital medical care unit. Eur J Emerg Med 2003;10(2):87-93.

14. Gaszynski T, Tokarz A, Piotrowski D, Machala W. Boussignac CPAP in the postoperative period in morbidly obese patients. Obes Surg 2007; 17(4):452-456.

15. Dieperink W, Nijsten MW, van de Stadt M, van der Horst IC, Aarts $\mathrm{LP}, \mathrm{Zij}$ lstra F, et al. Implementation of Boussignac continuous positive airway pressure in the coronary care unit: experiences and attitudes. Heart Lung 2008;37(6):449-454.

16. Templier F, Dolveck F, Baer M, Chauvin M, Fletcher D. [Laboratory testing measurement of $\mathrm{F}_{\mathrm{IO}_{2}}$ delivered by Boussignac CPAP system with an input of $100 \%$ oxygen]. Ann Fr Anesth Reanim 2003;22(2): 103-107. Article in French.

17. Moritz F, Brousse B, Gellée B, Chajara A, L'Her E, Hellot MF, Bénichou J. Continuous positive airway pressure versus bilevel noninvasive ventilation in acute cardiogenic pulmonary edema: a randomized multicenter trial. Ann Emerg Med 2007;50(6):666-675.

18. Borg G. Borg's perceived exertion and pain scales. Champaign, IL: Human Kinetics; 1998:39-52.

19. Sehlin M, Ohberg F, Johansson G, Winso O. Physiological responses to positive expiratory pressure breathing: a comparison of the PEP bottle and the PEP mask. Respir Care 2007;52(8):1000-1005.

20. Barbini P, Cevenini G, Lutchen KR, Ursino M. Estimating respiratory mechanical parameters of ventilated patients: a critical study in the routine intensive-care unit. Med Biol Eng Comput 1994;32(2): 153-160.

21. Avanzolini G, Barbini P, Cappello A, Cevenini G, Chiari L. A new approach for tracking respiratory mechanical parameters in real-time. Ann Biomed Eng 1997;25(1):154-163.

22. Gherini S, Peters RM, Virgilio RW. Mechanical work on the lungs and work of breathing with positive end-expiratory pressure and continuous positive airway pressure. Chest 1979;76(3):251-256. 